\title{
Study on Permeability and Blocking Resistance of Composite Specimen with Double-Layer Permeable Asphalt Mixture
}

\author{
Xiaoge Tian $\mathbb{D}^{1,2}$ Huitong Yuan, ${ }^{2}$ Ren $\mathrm{Zhang}^{2}$ Yichao $\mathrm{Xu}^{2}{ }^{2}$ and Xiaofei Wang ${ }^{2}$ \\ ${ }^{1}$ State Engineering Laboratory of Highway Maintenance Technology, Changsha University of Science \& Technology, Changsha, \\ Hunan 410114, China \\ ${ }^{2}$ School of Traffic and Transportation Engineering, Changsha University of Science \& Technology, Changsha, \\ Hunan 410114, China \\ Correspondence should be addressed to Xiaoge Tian; tianxiaoge@126.com
}

Received 29 March 2019; Accepted 12 May 2019; Published 29 May 2019

Academic Editor: Robert Černý

Copyright $\odot 2019$ Xiaoge Tian et al. This is an open access article distributed under the Creative Commons Attribution License, which permits unrestricted use, distribution, and reproduction in any medium, provided the original work is properly cited.

\begin{abstract}
In order to study the permeability and antiblocking performance of composite specimens with double-layer permeable asphalt mixture, three types of PAC-10 asphalt mixture with different target porosity $(20 \%, 22 \%$, and $24 \%)$ and PAC-16 asphalt mixture with a target porosity of $22 \%$ were designed, and the double-layer Marshall specimen was fabricated through "hot + hot" method. Their orthogonal vertical sections were scanned with X-ray CT. The pore distribution and its characteristics of the specimens were analyzed by digital image analysis technology. The permeability of composite specimens was studied through penetration test, and their blocking resistances were studied through using different particle sizes of fine machine-made sands as blocking materials. The results show that the permeable capacity increases linearly with the increase of porosity. The permeable capacity of PAC-16 with $22 \%$ porosity is greater than PAC- $10(20 \%, 22 \%$, and $24 \%)$ porosity. The porosity of the upper layer increases, and the permeability of the double-layer composite samples increases linearly. The critical particle size causing blocking is $0.15 \mathrm{~mm}$, followed by $0.3 \mathrm{~mm}$. The vertical permeability coefficient decreases exponentially with the increasing of blocking times.
\end{abstract}

\section{Introduction}

Permeable asphalt pavement is a hot issue at home and abroad $[1,2]$. Single-layer permeable asphalt pavement is widely used in research and application. Its porosity is generally $18 \%-25 \%$, and its seepage ability is strong enough to quickly drain out the water on the pavement surface, reduce the thickness of water film, ensure sufficient tire friction, reduce water mist, water splash, and glare; so, it can improve driving safety and reduce accident rate by $85 \%$ $[1,3-6]$. However, it is found that the pores in the singlelayer permeable asphalt pavement are easily blocked during its service period by dust, chips, tire wear, grease, etc., and gradually lose its excellent permeable capacity [7-11].

In order to solve this problem, a double-layer permeable asphalt pavement was proposed [12-14]. The upper layer is composed of porous asphalt mixture with more pores, and their size is smaller. The lower layer porous asphalt mixture has larger pores, strong permeable capacity, and antiblocking ability. So, the upper layer can prevent large-size dust particle from entering the lower layer, just like a sieve. While the lower layer can discharge the small particle size blocking material infiltrated from the upper layer pores under the action of water or air flow, so as to reduce the probability of blocking. At the same time, compared with the traditional single-layer permeable asphalt pavement, double-layer permeable asphalt pavement has better noise reduction, permeability, slip resistance, and durability [12, 14-16]. Kragh and Bendtsen investigated the life and acoustic characteristics of double-layer permeable asphalt pavement. It was found that the service life of double-layer permeable asphalt pavement was prolonged, the level of road noise reduction gradually decreased in the first three years after paving, and the noise reduction level tended to be stable after three years [14]. Hamzah et al. compared the blocking resistances of double-layer porous asphalt mixture and 
single-layer porous asphalt mixture with different particle sizes and different upper thicknesses through indoor simulated blocking tests. The results showed that a longer time should be taken to clog the composite samples with a thinner upper layer, and the double-layer porous asphalt mixture had better blocking resistance than the single-layer porous asphalt mixture [12].

\section{Raw Materials}

2.1. Coarse Aggregate. Coarse aggregates crushed with limestone were adopted in the paper, and their technical indexes are shown in Table 1 [11].

2.2. Fine Aggregate. Machine-made sand with limestone and their technical indexes are shown in Table 2 [11].

\subsection{Filler}

2.3.1. Mineral Powder. Grind with limestone and its main indexes are shown in Table 3.

2.3.2. Slaked Lime. In order to enhance the adhesion between asphalt binder and aggregate, slaked lime was used to replace part of mineral powder (the amount of slaked lime is $3 \%$ of the mass of the asphalt mixture) to improve the spalling resistance of the mixture.

2.3.3. High-Viscosity Modified Asphalt. Compared with the traditional dense-graded asphalt mixture, the permeable asphalt mixture belongs to the skeleton-pore structure, and the coarse aggregates were in point-to-point contact state. The strength mainly depended on the bonding performance of asphalt binder, so high-viscosity asphalt binder was necessary to be used. The dynamic viscosity of asphalt at $60^{\circ} \mathrm{C}$ should be greater than $20,000 \mathrm{~Pa} \cdot \mathrm{s}$ in both Chinese and Japanese specifications.

The high-viscosity asphalt binder produced by Taihe Asphalt Products Co. Ltd. was used. Its technical indexes are shown in Table 4.

\section{Mix Design of Permeable Asphalt Mixture}

According to the common structure and material composition of the double-layer permeable asphalt pavement, asphalt mixture, PAC-10, was selected as the upper layer, and its designed porosity was $20 \%, 22 \%$, and $24 \%$, respectively. PAC-16 with a designed porosity of $22 \%$ was used for the lower layer.

According to Chinese Technical Specifications for Construction of Highway Asphalt Pavement [17], their gradations of aggregates were prepared, as shown in Table 5.

3.1. Determination of the Optimum Asphalt Content. According to Chinese Technical Specifications for Construction of Highway Asphalt Pavement [17], the leakage test and the scattering test are, respectively, used to control the
TABle 1: Technical indexes of coarse aggregates.

\begin{tabular}{lcc}
\hline Indexes & Unit & $\begin{array}{c}\text { Actual } \\
\text { measurement }\end{array}$ \\
\hline Crushing value & $\%$ & 13.5 \\
Apparent relative density & - & - \\
Water absorption & $\%$ & 1.2 \\
Strength & $\%$ & 9.4 \\
Needle and plate particle content & $\%$ & 8 \\
Content of <0.075 mm material & $\%$ & 0.43 \\
Adhesion with SBS modified asphalt & Level & 5 \\
\hline
\end{tabular}

maximum asphalt content and the minimum asphalt content of the mixture, and the requirements of designed porosity, interconnected porosity, and Marshall stability were adopted to determine the optimum asphalt content [18].

Assume that the asphalt film thickness, $h$, was $14 \mu \mathrm{m}$, according to the gradations, the calculated initial asphalt contents, $P_{b}$, of gradations according to formulas (1) and (2) were $4.6 \%, 4.4 \%, 3.2 \%$, and $3.4 \%$, respectively. Marshall specimens were compacted through the compaction method, and the porosity was $19.8 \%, 21.7 \%, 24.1 \%$, and $22.6 \%$, respectively. The target porosity was close to the designed, so the gradations listed in Table 5 were the final gradation:

$$
A=\frac{(2+0.02 a+0.04 b+0.08 c+0.14 d+0.3 e+0.6 f+1.6 g)}{48.74},
$$

$P_{b}=h \times A$,

where $A$ is the total surface area of aggregates and $a, b, c, d$, $e, f$, and $g$ are the passing rates of sieve size of $4.75 \mathrm{~mm}$, $2.36 \mathrm{~mm}, 1.18 \mathrm{~mm}, 0.6 \mathrm{~mm}, 0.3 \mathrm{~mm}, 0.15 \mathrm{~mm}$, and $0.075 \mathrm{~mm}$, respectively.

For each gradation, based on the calculated initial asphalt content, five groups of Marshall specimens were molded with different asphalt content. The interval of asphalt content was $0.4 \%$. Then, Marshall test, leakage test, and Kentarou dispersion test were conducted. The variations of leakage of asphalt binder and dispersion of asphalt mixture with asphalt contents are shown in Figure 1. The variation of porosity and interconnected porosity with asphalt content are shown in Figure 2.

It can be seen from Figures 1 and 2 that the leakage of permeable asphalt mixture increases with the increase of asphalt contents, and the dispersion loss decreases with the increase of asphalt contents. The porosities and interconnected porosities decrease with the increases of asphalt contents. So, according to Chinese Technical Specifications for Asphalt Pavement Construction, the optimum asphalt content for gradation 1 to gradation 4 is $4.4 \%, 4.2 \%, 3.2 \%$, and $3.4 \%$, respectively.

The performance of the PAC mixtures at the optimum asphalt content is shown in Table 6, which meets the requirements.

It can be seen from Table 6 that the designed PAC- 10 and PAC-16 mixtures meet the designed requirements and have 
TABle 2: Main technical indicators of fine aggregates.

\begin{tabular}{lcccc}
\hline Material particle size $(\mathrm{mm})$ & $\begin{array}{c}\text { Apparent relative } \\
\text { density }\end{array}$ & Surface relative density & Gross volume relative density Water absorption rate (\%) \\
\hline 1.18 & 2.702 & 2.672 & 2.654 & - \\
0.6 & 2.723 & 2.683 & 2.661 & - \\
0.3 & 2.740 & 2.707 & 2.688 & - \\
0.15 & 2.728 & 2.701 & 2.689 & - \\
0.075 & 2.721 & 2.693 & 2.676 & - \\
\hline
\end{tabular}

TABLE 3: Results of limestone ore powder test.

\begin{tabular}{lccc}
\hline Project & Unit & Test results & Requirements \\
\hline Apparent density & $\mathrm{g} / \mathrm{cm}^{3}$ & 2.716 & $\geq 2.50$ \\
Size range & & & 100 \\
$\quad<0.6 \mathrm{~mm}$ & $\%$ & 94.5 & 100 \\
$<0.15 \mathrm{~mm}$ & $\%$ & 90 & $90 \sim 100$ \\
$\quad<0.075 \mathrm{~mm}$ & $\%$ & 0.41 & $75 \sim 100$ \\
Water content & $\%$ & 2 & $\leq 1$ \\
Plasticity index & - & 0.5 & $<4$ \\
Hydrophilic coefficient & - & No agglomeration & $<1$ \\
Exterior & - & & No agglomeration \\
\hline
\end{tabular}

TABLE 4: Technical indexes of high-viscosity asphalt binder.

\begin{tabular}{lcccc}
\hline Indexes & Unit & $10 \% \mathrm{GH}-1$ & $12 \% \mathrm{GH}-1$ \\
\hline Penetration $\left(25^{\circ} \mathrm{C}, 5 \mathrm{~s}, 100 \mathrm{~g}\right)$ & $0.1 \mathrm{~mm}$ & 53.3 & 49.5 & 89.6 \\
Softening point & ${ }^{\circ} \mathrm{C}$ & 82.7 & 90147 & 44.2 \\
Dynamic viscosity at $60^{\circ} \mathrm{C}$ & $\mathrm{Pa} \cdot \mathrm{s}$ & 54790 & 4.562 & 92.1 \\
Brookfield viscosity at $135^{\circ} \mathrm{C}$ & $\mathrm{Pa} \cdot \mathrm{s}$ & 4.746 & 2.308 & 5.671 \\
Brookfield viscosity at $180^{\circ} \mathrm{C}$ & $\mathrm{Pa} \cdot \mathrm{s}$ & 2.215 & 96.6 \\
Elastic recovery & $\%$ & 95.9 & 2.771 \\
\hline
\end{tabular}

TABLE 5: Gradations of permeable asphalt mixture.

\begin{tabular}{|c|c|c|c|c|c|c|c|c|c|c|c|c|c|}
\hline \multirow{2}{*}{ Number } & \multirow{2}{*}{ Mix type } & \multirow{2}{*}{ Target porosity (\%) } & \multicolumn{11}{|c|}{ The percentage of mass passing through the following sieve holes (\%) } \\
\hline & & & 19 & 16 & 13.2 & 9.5 & 4.75 & 2.36 & 1.18 & 0.6 & 0.3 & 0.15 & 0.075 \\
\hline 1 & & 20 & 100 & 100 & 100 & 90 & 50 & 13 & 7.6 & 6.5 & 5.5 & 5 & 4 \\
\hline 2 & PAC-10 & 22 & 100 & 100 & 100 & 90 & 50 & 11.3 & 6 & 4.7 & 4.7 & 4.7 & 4 \\
\hline 3 & & 24 & 100 & 100 & 100 & 90 & 50 & 10 & 6 & 4.1 & 3.3 & 3.3 & 2.3 \\
\hline 4 & PAC-16 & 22 & 100 & 90 & 70 & 45 & 12 & 10 & 6 & 4.3 & 3.8 & 3.8 & 3 \\
\hline
\end{tabular}

high interconnected porosities, and all of the performances meet the specifications.

\section{Permeability of Double-Layer Compound Specimen}

4.1. Method for Preparing Double-Layer Compound Specimen. There is no specific preparation method for the double-layer Marshall specimen in the current specification. The "hot + hot" preparing method was utilized in this paper. The overall height of the double-layer specimen was $63.5 \mathrm{~mm}$, and the height of the upper layer (PAC-10) and the lower layer (PAC-16) was determined to be $23.5 \mathrm{~mm}$ and $40 \mathrm{~mm}$, respectively. The masses of the upper layer and lower layer were calculated according to the density of PAC-10 and PAC-16. Mixing and pouring the PAC-16 mixture into the mold, tamping and leveling its surface, immediately putting it into the oven at $175^{\circ} \mathrm{C}$, then mixing PAC- 13 mixture, pulling out the mold and filling PAC-13 mixture into it, tamping and leveling the surface, and compacting the surface for 50 times. So, a double-layer compound Marshall specimen was obtained.

4.2. Analysis of Pore Characteristics Based on CT Technology. The computed tomography (CT) scanning technique was used to detect nondestructively the internal structure of the compound specimen. The X-ray CT scanning system is shown in Figure 3.

4.2.1. Scanning Sections. The double-layer specimens were $\mathrm{X}$-ray CT scanned to obtain the characteristics and 


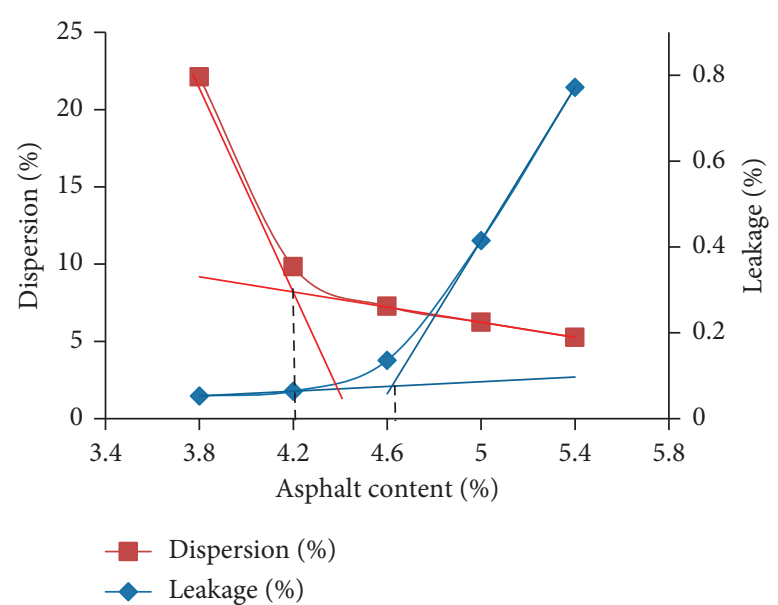

(a)

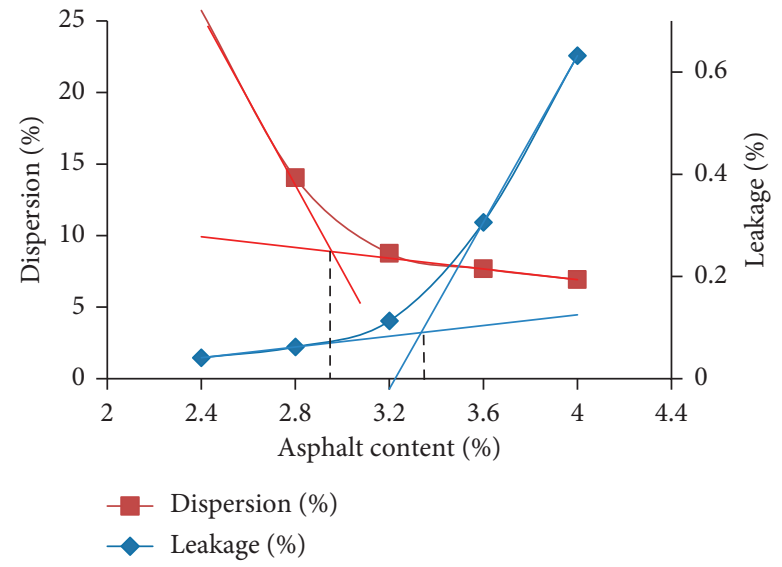

(c)

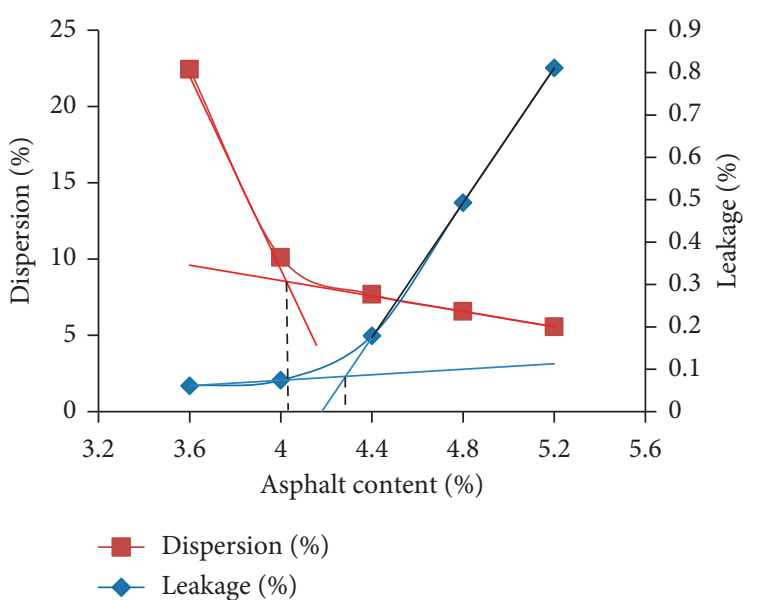

(b)

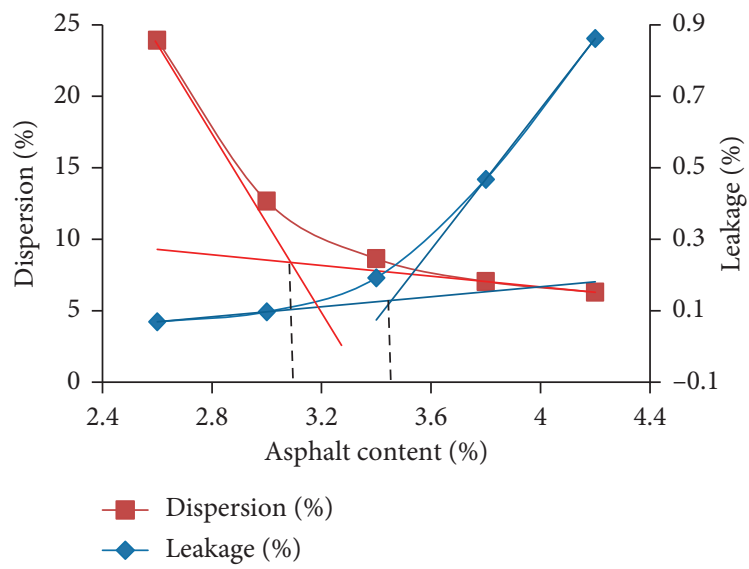

(d)

Figure 1: Relationship between leakage, dispersion, and asphalt content: (a) 20\% PAC-10, (b) 22\% PAC-10, (c) 24\% PAC-10, and (d) PAC-16.

distribution of internal pores. Because the main purpose of this paper was to study the top-to-bottom pore characteristics relating to permeability and antiblocking, two orthogonal vertical sections of each specimen were scanned, as shown in Figure 4.

4.2.2. Analysis of Scanning Results. CT images of the two orthogonal vertical sections of each compound specimen are shown in Figure 5.

The CT images were analyzed, and the pore characteristics were statisticised with software ImageJ-pro. The statistical pore characteristics for each section are shown in Table 7 .

It can be found from Table 7 that the statistical parameters of pores, such as the size, quantity, distribution, porosity, and connected porosity of the specimens, are related to the scanned section. There are large differences in different sections of the same specimen. The distribution of pores is random. The larger the designed void ratio is, the relatively larger the number, the area, the equivalent diameter, and the connected porosity are. Therefore, it is conducive to drainage.

\section{Study on Permeability of Double-Layer Compound Specimen}

For the single-layer specimen and the double-layer composite specimen (their heights are the same, $63.5 \mathrm{~mm}$ ), the vertical permeability coefficient is tested on the specimen before being demolded. The test results are shown in Table 8 .

It can be seen from Table 8 and Figure 6 that (1) when the porosity of the lower mixture is constant, the permeability of the double-layer compound specimen increases with the increase of the porosity of the upper layer mixture, showing a good linear relationship and (2) the drainage capacity of the double-layer compound specimen is larger than that of the single-layer specimen. This is because their total thicknesses are the same, and the pore characteristics of the whole single-layer specimen are the same, while the lower part of the double-layer specimen has a larger porosity, so that it is easier to drain.

\section{Blocking Characteristics of Double-Layer Compound Specimen}

6.1. Blocking Material. Dust, chips, tire abrasives, grease, etc., will be brought into the internal pores in permeable 


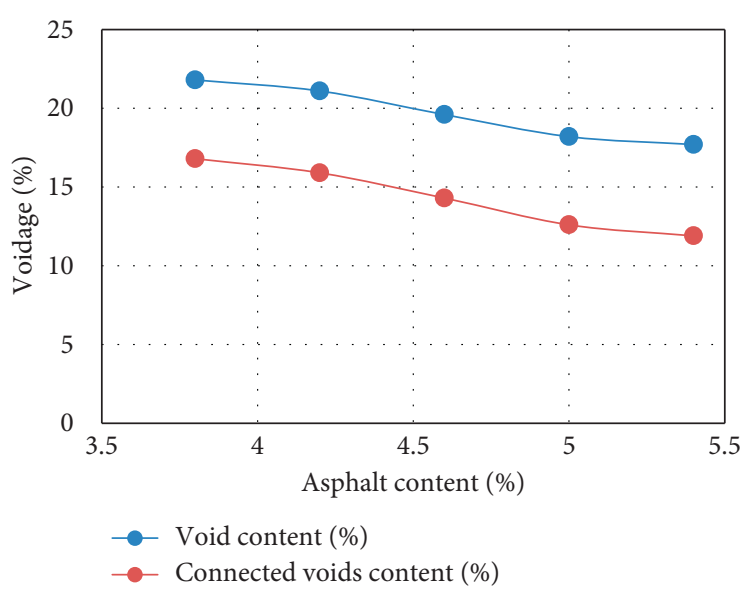

(a)

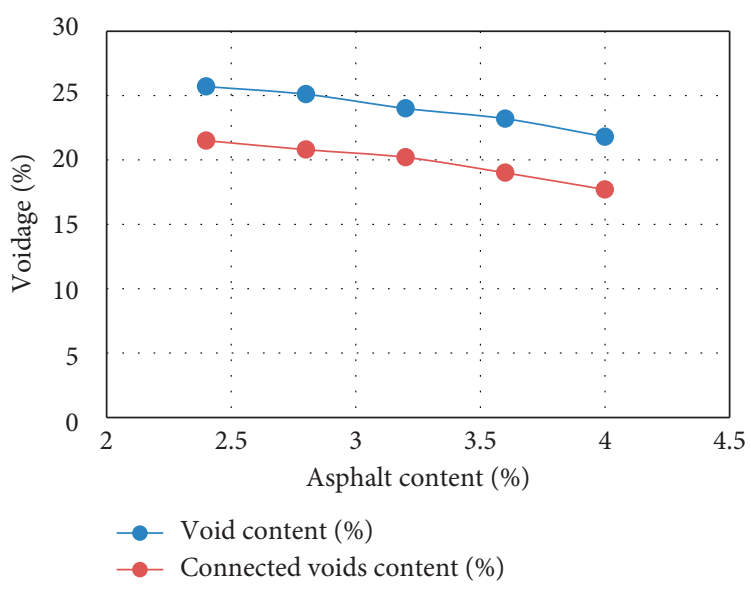

(c)

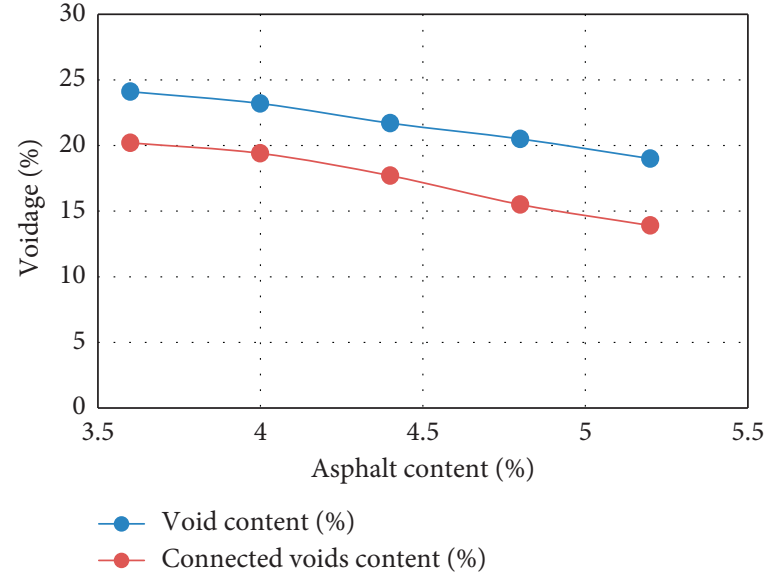

(b)

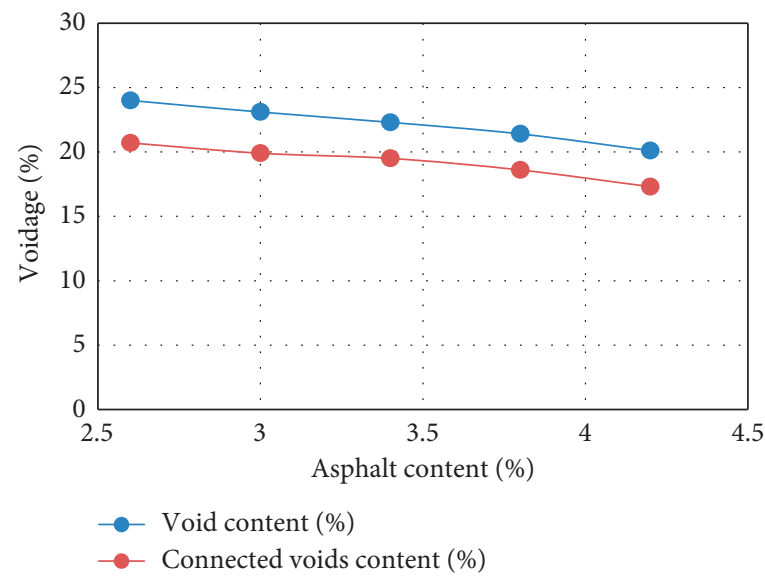

(d)

Figure 2: Relationship between porosity and asphalt content: (a) 20\% PAC-10, (b) 22\% PAC-10, (c) 24\% PAC-10, and (d) PAC-16.

TABle 6: Performance of PAC mixtures with optimal asphalt content.

\begin{tabular}{|c|c|c|c|c|c|}
\hline Mixtures & $20 \%$ PAC- 10 & $22 \%$ PAC- 10 & $24 \%$ PAC- 10 & PAC-16 (22\%) & Specification \\
\hline Optimal asphalt content (\%) & 4.4 & 4.2 & 3.2 & 3.4 & - \\
\hline Porosity $(\%)$ & 20.3 & 22.2 & 24.0 & 22.3 & - \\
\hline Interconnected porosity (\%) & 15.2 & 18.43 & 20.2 & 19.5 & $\geq 14$ \\
\hline Leakage (\%) & 0.110 & 0.132 & 0.113 & 0.192 & $<0.3$ \\
\hline Dispersion (\%) & 8.64 & 8.93 & 8.75 & 8.64 & $<20$ \\
\hline Stability $(\mathrm{kN})$ & 7.06 & 5.72 & 5.17 & 5.51 & $\geq 5$ \\
\hline
\end{tabular}

asphalt mixture under the action of driving and water flow, forming a blockage. In order to study the blocking characteristics of permeable asphalt mixtures, it is necessary to select suitable blocking materials to simulate the blockage at the site. Hamzah et al. used an aqueous solution of clay and sand as the blocking material. Both the clay and the sand were graded, respectively, and the concentration was $1.5 \mathrm{~g} / \mathrm{L}$ [12]. Jung et al. composed blocking fine materials with machine-made sands with a particle size of $2.36 \mathrm{~mm}$ to $0.075 \mathrm{~mm}$ [13].

In this paper, machine-made sands with different single particle sizes $(0.075 \mathrm{~mm} \sim 1.18 \mathrm{~mm})$ were selected as different blocking materials.
6.2. Blockage Test Scheme. The blocking materials were divided into 5 grams each in advance. The first blocking material was spreaded evenly on the surface of the specimen, and the specimen was gently vibrated for $3 \mathrm{~s}$, then $200 \mathrm{ml}$ of water was slowly and evenly poured, so that the blocking material can infiltrate into the pores. The seepage coefficient after the first blocking was tested. The above operations were repeated for five times.

6.3. Results of Blocking Test. The vertical permeability coefficients of different combinations of the double-layer compound specimen, (20\%, 22\%, and 24\%) PAC-10+22\% 


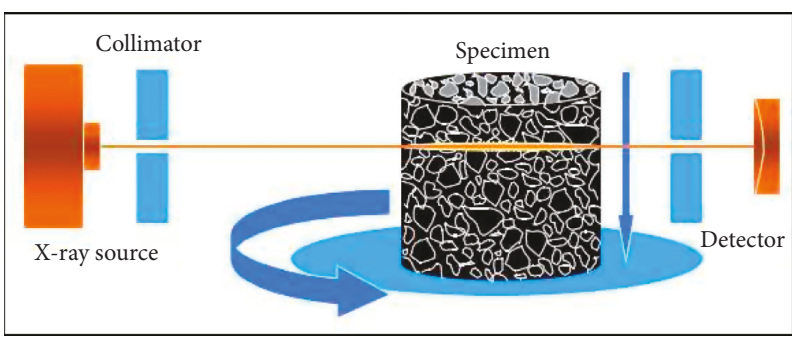

Figure 3: X-ray CT scanning system.
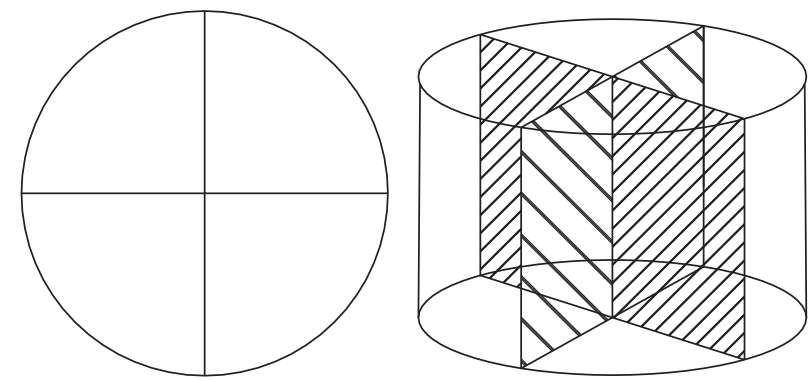

FIGURE 4: Scanned sections of the specimen.

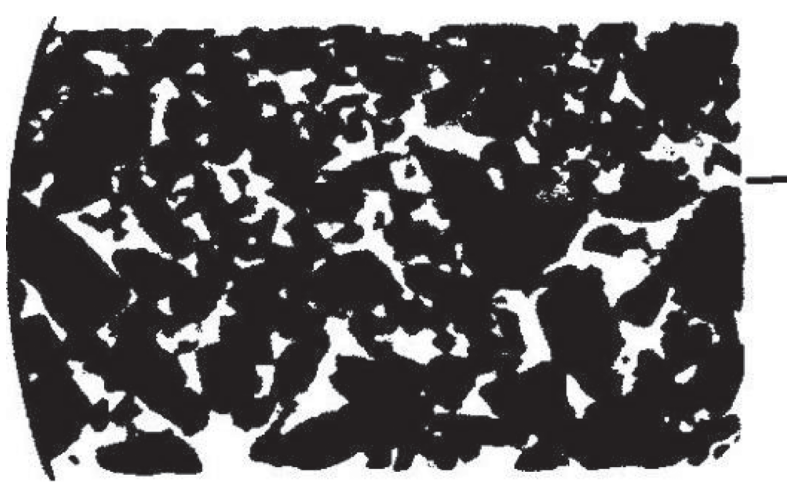

(a)

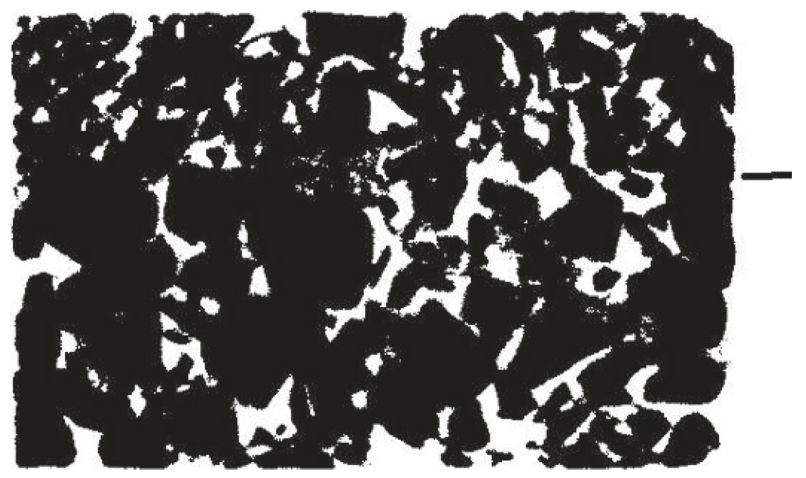

(c)

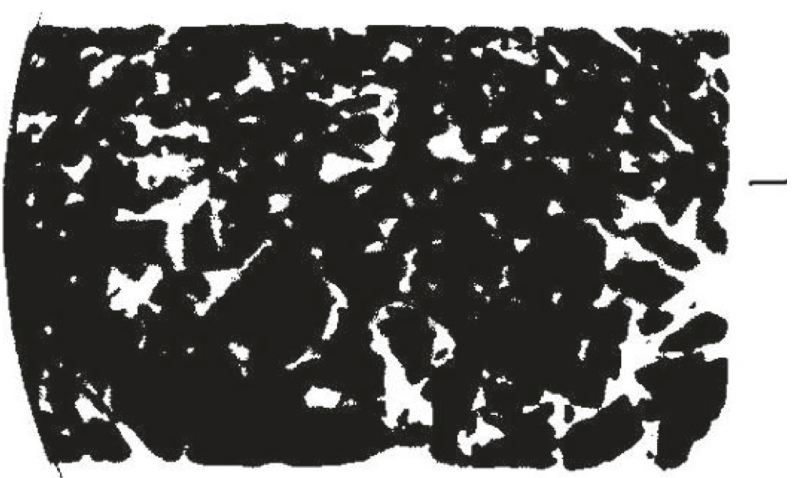

(b)

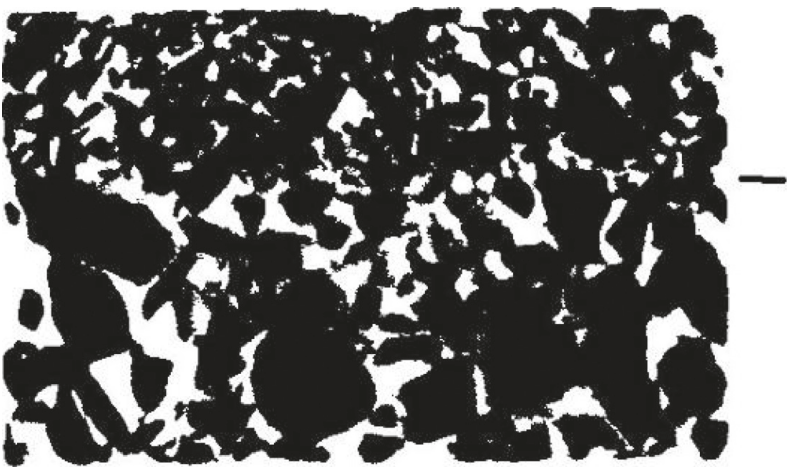

(d)

FIgURE 5: Continued. 


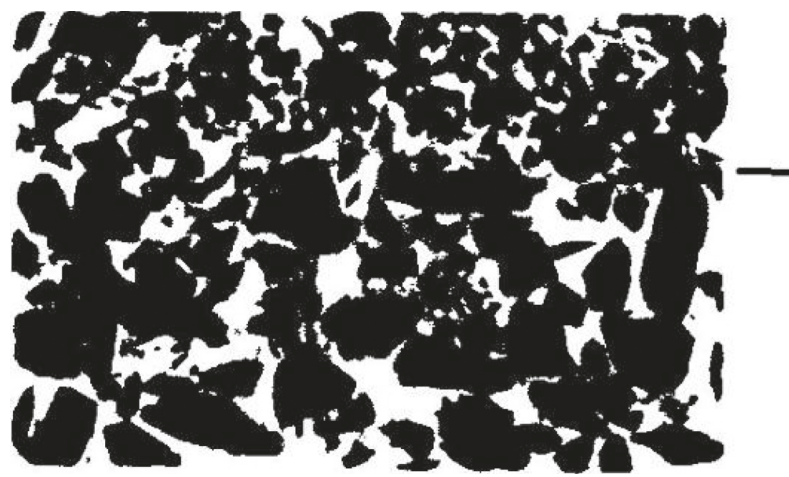

(e)

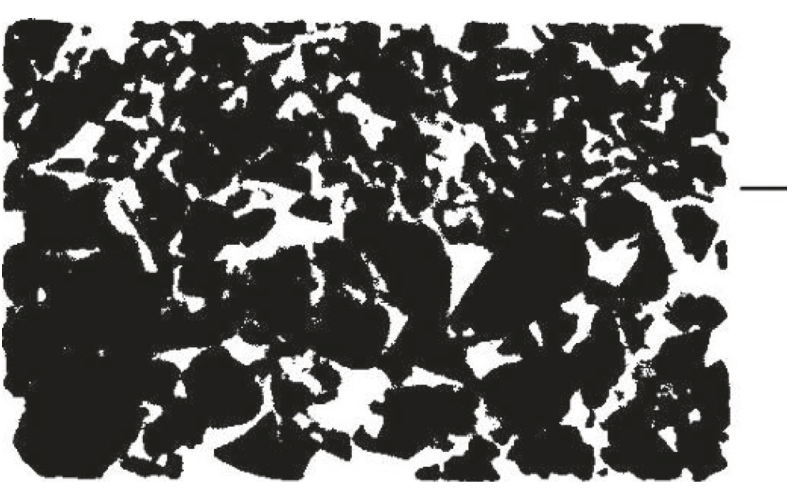

(f)

Figure 5: CT images of compound specimens: (a) $(20 \%+22 \%)-1 \#$, (b) $(20 \%+22 \%)-2 \#$, (c) $(22 \%+22 \%)-1 \#$, (d) $(22 \%+22 \%)-2 \#$, (e) $(24 \%+22 \%)-1 \#$, and (f) $(24 \%+22 \%)-2 \#$.

TABLE 7: Statistical pore characteristics in composite specimens.

\begin{tabular}{lcccccc}
\hline Specimen type & $\begin{array}{c}\text { Porosity } \\
(\%)\end{array}$ & $\begin{array}{c}\text { Number of } \\
\text { pores }(a)\end{array}$ & $\begin{array}{c}\text { Total area of } \\
\text { pores }\left(\mathrm{mm}^{2}\right)\end{array}$ & $\begin{array}{c}\text { Average single pore } \\
\text { area }\left(\mathrm{mm}^{2}\right)\end{array}$ & $\begin{array}{c}\text { Equivalent } \\
\text { diameter }(\mathrm{mm})\end{array}$ & $\begin{array}{c}\text { Quantity ratio of pore area } \\
\text { less than } 0.09 \mathrm{~mm}^{2}\end{array}$ \\
\hline$(20 \%+22 \%)-1$ & 19.82 & 618 & 1290.0025 & 4.06 & 2.27 & 1.74 \\
$(20 \%+22 \%)-2$ & 12.26 & 526 & 782.1613 & 2.4 & 2.005 & 20.0 \\
Average value & 16.04 & 572 & 1036.0819 & 3.23 & 1.46 & 17.5 \\
$(22 \%+22 \%)-1$ & 16.64 & 619 & 1046.7975 & 1.69 & 1.36 & 38.7 \\
$(22 \%+22 \%)-2$ & 21.43 & 1049 & 1530.9850 & 1.46 & 1.41 & 39.3 \\
Average value & 19.035 & 818 & 1288.8913 & 1.575 & 1.64 & 1.24 \\
$(24 \%+22 \%)-1$ & 24.99 & 842 & 1785.3025 & 1.25 & 31.3 \\
(24\%+22\%)-2 & 21.59 & 1282 & 1537.8113 & 1.66 & 1.44 & 25.1 \\
Average value & 23.29 & 1001 & 1661.5569 & & \\
\hline
\end{tabular}

TABLE 8: Vertical permeability coefficient of specimen.

\begin{tabular}{lc}
\hline Type of specimen & Permeability $(\mathrm{ml} / \mathrm{s})$ \\
\hline $20 \%$ PAC- $10+22 \%$ PAC- 16 & 77.318 \\
$22 \%$ PAC- $10+22 \%$ PAC-16 & 88.082 \\
$24 \%$ PAC- $10+22 \%$ PAC- 16 & 106.763 \\
$20 \%$ PAC- 10 & 46.926 \\
$22 \%$ PAC-10 & 54.146 \\
$24 \%$ PAC- 10 & 61.289 \\
$22 \%$ PAC- 16 & 111.896 \\
\hline
\end{tabular}

PAC-16, and their variations with the blocking times are shown in Figure 7.

These can be found from Figure 7 the following:

(1) The vertical permeability coefficient of double-layer compound specimen has a good correlation with the blocking times. With the increase of the blocking times, the vertical permeability coefficient decreases continuously.

(2) The decrease of vertical permeability coefficient of double-layer specimens is the fastest when the blocking material with particle size of $0.15 \mathrm{~mm}$ is used.

(3) The key particle size blocking the pore in PAC$10+$ PAC-16 double-layer compound specimen is $0.15 \mathrm{~mm} \sim 0.3 \mathrm{~mm}$, followed by $0.3 \mathrm{~mm} \sim 0.6 \mathrm{~mm}$. For blocking materials of smaller than $0.075 \mathrm{~mm}$, most of

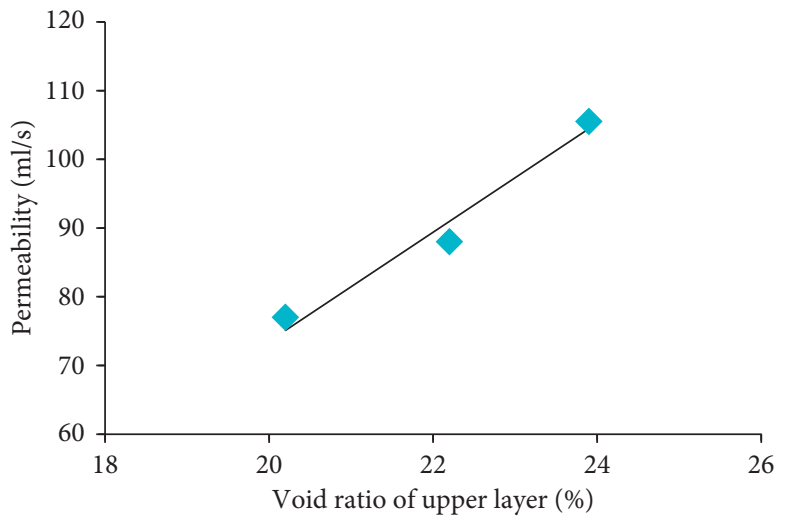

FIGURE 6: Relationship between permeability of compound specimen and porosity of the upper layer mixture.

them can flow out of the specimen through the interconnected pores under the pressure of water and/or air flow.

(4) The vertical permeability coefficients before and after blocking increase with the increase of the porosity of the upper layer mixture, and they have a good linear correlationship.

6.4. Comparison of Blocking Resistance between Double-Layer Compound Specimen (PAC-10+PAC-16) and Single-Layer 


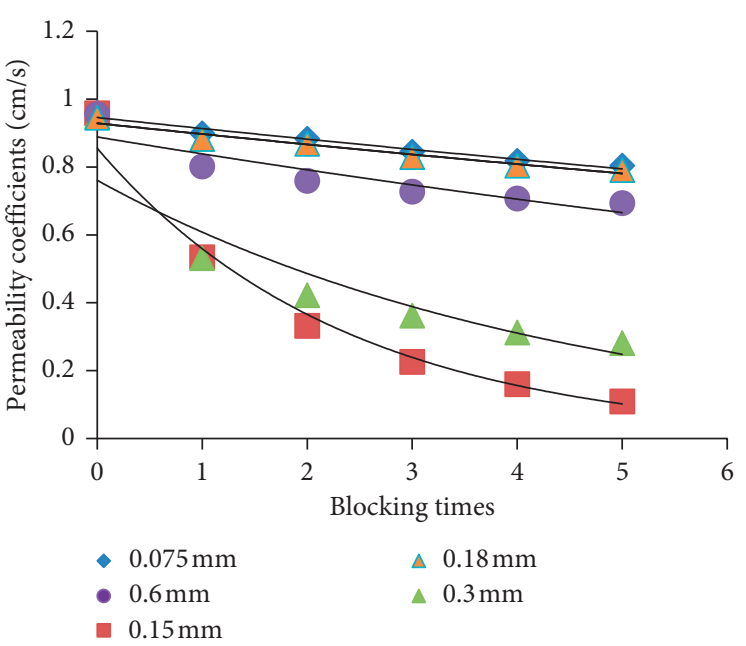

(a)

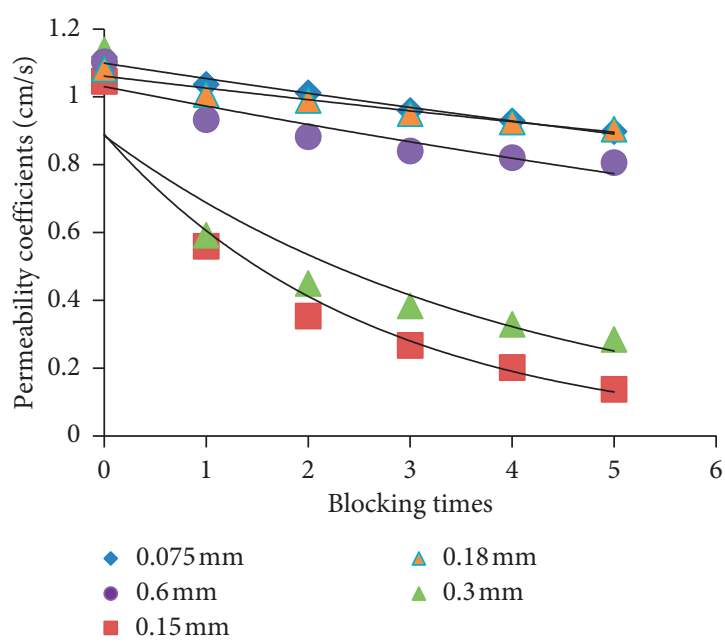

(b)

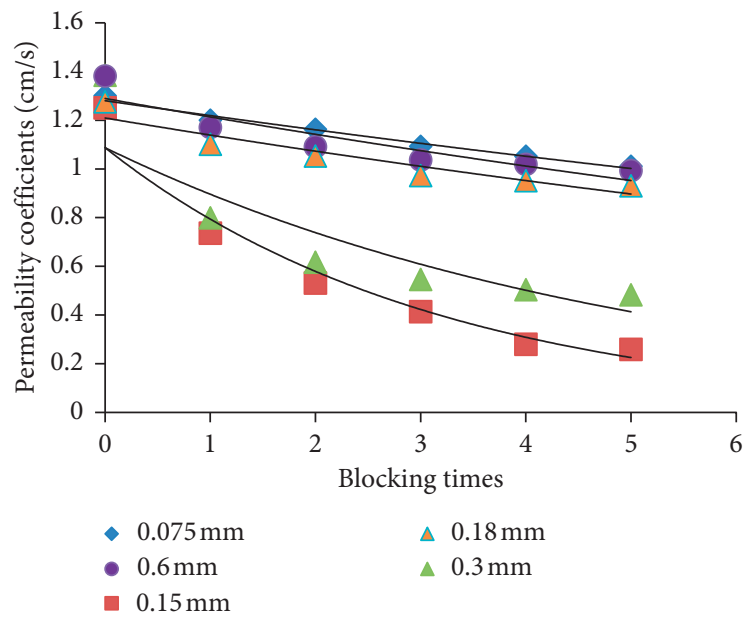

(c)

Figure 7: Relationship between vertical permeability coefficient and blocking times: (a) 20\% PAC-10 + 22\% PAC-13, (b) 22\% PAC-10 + 22\% PAC-13, and (c) 24\% PAC-10 + 22\% PAC- 13 .

Specimen (PAC-10). The blocking test was conducted on single-layer (PAC-10) specimens (thickness is $63.5 \mathrm{~mm}$ ) with blocking material, and its particle size is $0.15 \mathrm{~mm}$. The results are shown in Table 9.

It can be found from Figure 8 that the vertical permeability coefficient of the single-layer specimen also increases with the increase of the porosity, which is consistent with the variation trend of the double-layer compound specimen. Under the same number of blocking times, the vertical permeability coefficient of double-layer compound specimen, PAC-10+PAC-16, is significantly larger than the vertical permeability coefficient of single-layer specimen, PAC-10, which is consistent with the porosity of the upper layer. This indicates that, within a certain range, the permeability of the compound specimen is greater than that of the single-layer specimen with the same thickness.

\section{Conclusions}

(1) Through the permeable test, it is found that the permeability coefficient of PAC-16 asphalt mixture with a designed porosity $22 \%$ is greater than that of PAC-10 asphalt mixture with the designed porosity $20 \%$ to $24 \%$.

(2) Under certain thickness, the permeability of the double-layer compound specimen increases linearly with the increase of the porosity of the upper layer mixture.

(3) The vertical permeability coefficient of the doublelayer compound specimen decreases with the increase of the number of blocking times. Both of the vertical permeability coefficients before and after blocking increase line with the increase of the porosity of the upper layer mixture.

(4) The key size of blocking material particles is $0.15 \mathrm{~mm}$, and the secondary particle size is $0.3 \mathrm{~mm}$. It is not easy to be washed out after they enter into the pores of the specimens. For blockage materials which particle size is or smaller than $0.075 \mathrm{~mm}$, most of them can flow out of the specimen through the connected porosity under the pressure of water and/or air flow. 


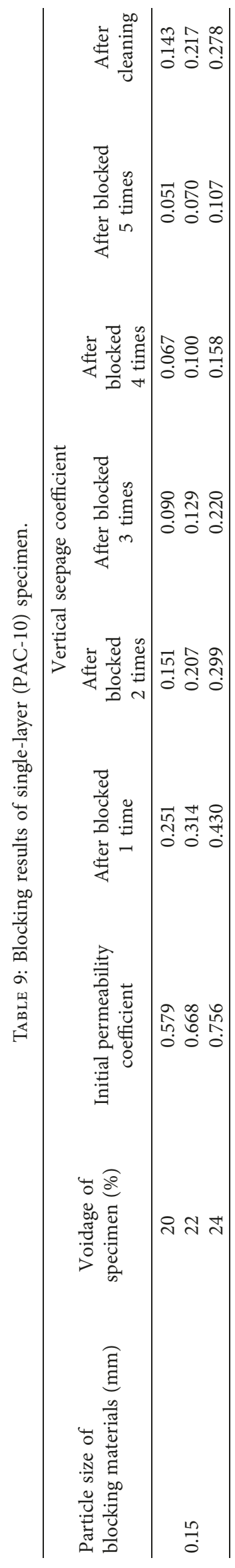




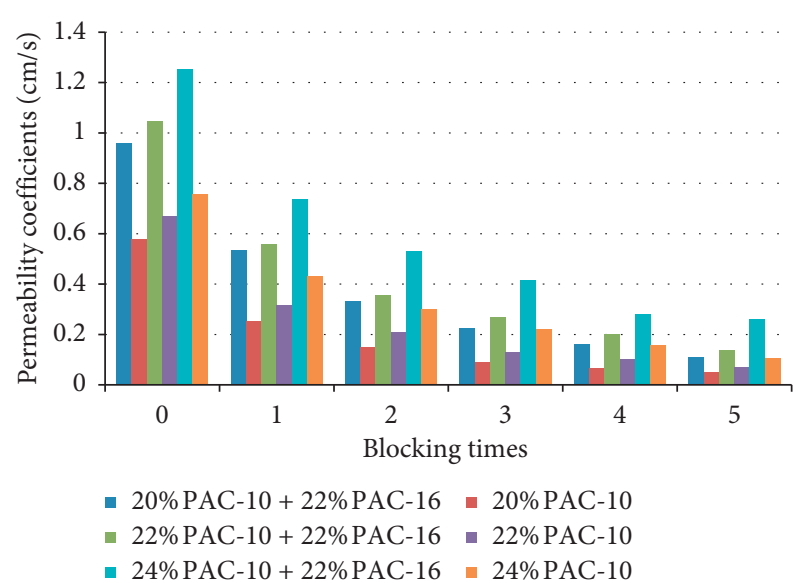

Figure 8: Comparison of blocking effect of double-layer and single-layer specimens.

(5) Before and after blocking, the vertical permeability coefficient of the double-layer compound specimen (PAC-10 + PAC-16) is significantly larger than the single-layer specimen (PAC-10) whose porosity is the same as that of the upper layer mixture of the compound specimen. The permeable capacity and blocking resistance of the double-layer permeable asphalt mixture is better than that of the single-layer permeable asphalt mixture.

\section{Data Availability}

The data used to support the findings of this study are available from the corresponding author upon request.

\section{Conflicts of Interest}

The authors declare that there are no conflicts of interest regarding the publication of this paper.

\section{Acknowledgments}

The authors appreciate the support of the National Natural Science Foundation of China (50878032).

\section{References}

[1] M. A. Hernandez-Saenz, S. Caro, E. Arámbula-Mercado, and A. Epps Martin, "Mix design, performance and maintenance of permeable friction courses (PFC) in the United States: state of the art," Construction and Building Materials, vol. 111, pp. 358-367, 2016.

[2] L. N. Antunes, E. Ghisi, and L. P. Thives, "Permeable pavements life cycle assessment: a literature review," Water, vol. 10, no. 11, p. 1575, 2018.

[3] X. Tian, Z. Ren, X. Yichao, C. Yantian, Y. Zhen, and Z. Shaohua, "Effect of warm-mix agent ec-120 on performance of asphalt binder and its microscopic mechanism," Advances in Civil Engineering, vol. 2019, Article ID 4365171, 7 pages, 2019.

[4] P. T. Weiss, M. Kayhanian, J. S. Gulliver, and L. Khazanovich, "Permeable pavement in northern North American urban areas: research review and knowledge gaps," International
Journal of Pavement Engineering, vol. 20, no. 2, pp. 143-162, 2019.

[5] R. A. Tarefder and M. Ahmad, "Evaluation of pore structure and its influence on permeability and moisture damage in asphalt concrete," International Journal of Pavement Engineering, vol. 18, no. 3, pp. 274-283, 2017.

[6] A. M. Al-Rubaei, A. L. Stenglein, M. Viklander, and G.-T. Blecken, "long-term hydraulic performance of porous asphalt pavements in Northern Sweden," Journal of Irrigation and Drainage Engineering, vol. 139, no. 6, pp. 499-505, 2013.

[7] M. Razzaghmanesh and S. Beecham, "A review of permeable pavement blocking investigations and recommended maintenance regimes," Water, vol. 10, no. 3, 2018.

[8] R. J. Winston, A. M. Al-Rubaei, G. T. Blecken, and W. F. Hunt, "A simple infiltration test for determination of permeable pavement maintenance needs," Journal of Environmental Engineering, vol. 142, no. 10, 2016.

[9] W. Jiang, A. Sha, J. Xiao, Y. Li, and Y. Huang, "Experimental study on filtration effect and mechanism of pavement runoff in permeable asphalt pavement," Construction and Building Materials, vol. 100, pp. 102-110, 2015.

[10] C. F. Yong, D. T. McCarthy, and A. Deletic, "Predicting physical clogging of porous and permeable pavements," Journal of Hydrology, vol. 481, pp. 48-55, 2013.

[11] X. Tian, Z. Ren, Y. Zhen, C. Yantian, X. Yichao, and Z. Qisen, "Multiscale study on the effect of nano-organic montmorillonite on the performance of rubber asphalt," Journal of Nanomaterials, vol. 2018, Article ID 9638603, 10 pages, 2018.

[12] M. Hamzah, N. Abdullah, J. Voskuilen, and G. van Bochove, "Laboratory simulation of the clogging behaviour of singlelayer and two-layer porous asphalt," Road Materials and Pavement Design, vol. 14, no. 1, pp. 107-125, 2013.

[13] J.-S. Jung, J.-R. Sohn, S.-H. Lee, and H.-S. Yang, "A case study on noise reduction effect of two-layer porous asphalt pavement in an urban area," International Journal of Highway Engineering, vol. 18, no. 5, pp. 49-56, 2016.

[14] J. Kragh and H. Bendtsen, " 3 Years' performance of twin-lay drainage asphalt in a city street," Proceedings Euronoise 2003. Neaples, 2003.

[15] X. Tian, H. Han, Q. Zhang, X. Li, and Y. Li, "Design and performance of anticracking asphalt-treated base," Advances in Materials Science and Engineering, vol. 2017, Article ID 2394945, 9 pages, 2017.

[16] X. Tian, Z. Ren, Y. Zhen, C. Yantian, Z. Shaohua, and $\mathrm{X}$. Yichao, "Simulation of bending fracture process of asphalt mixture semicircular specimen with extended finite element method," Advances in Materials Science and Engineering, vol. 2018, Article ID 4081264, 8 pages, 2018.

[17] China Communications Press, JTG F40-2004, Technical Specification for Construction of Highway Asphalt Pavement, China Communications Press, Beijing, China, 2004.

[18] China Communications Press, JTG E20-2011, Standard Test Methods of Bitumen and Bituminous Mixtures for Highway Engineering, China Communications Press, Beijing, China, 2011. 


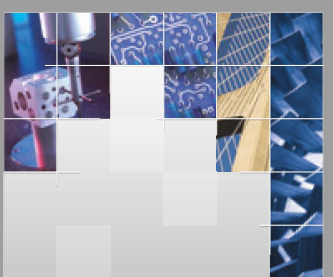

\section{Enfincering}
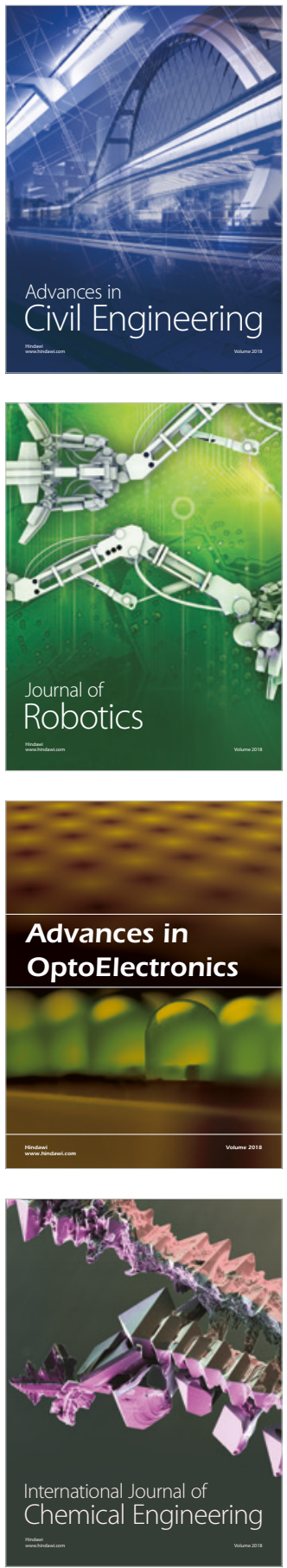

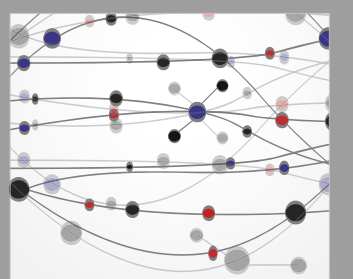

\section{Rotating \\ Machinery}

The Scientific World Journal

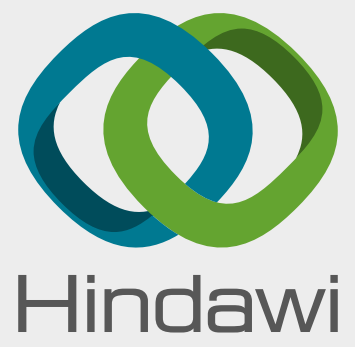

Submit your manuscripts at

www.hindawi.com
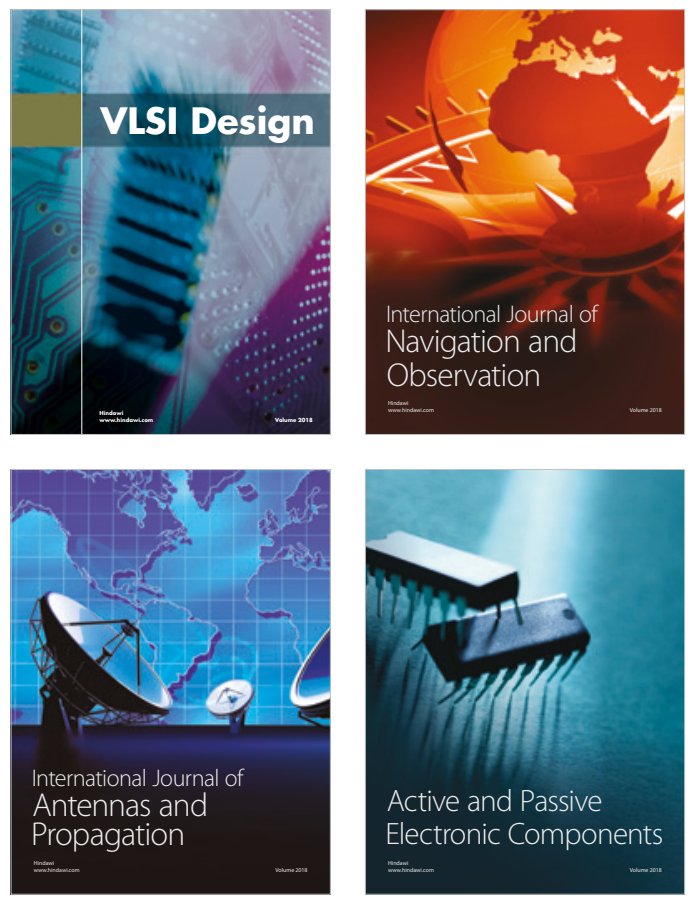
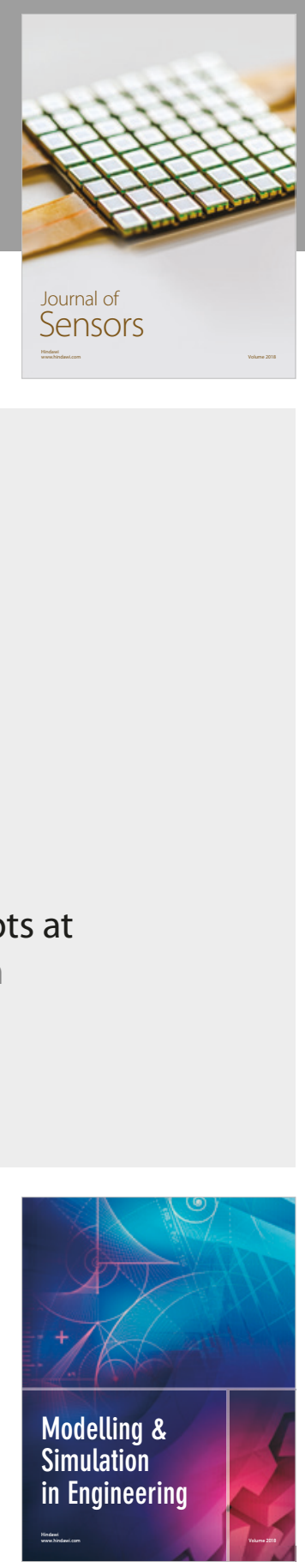

\section{Advances \\ Multimedia}
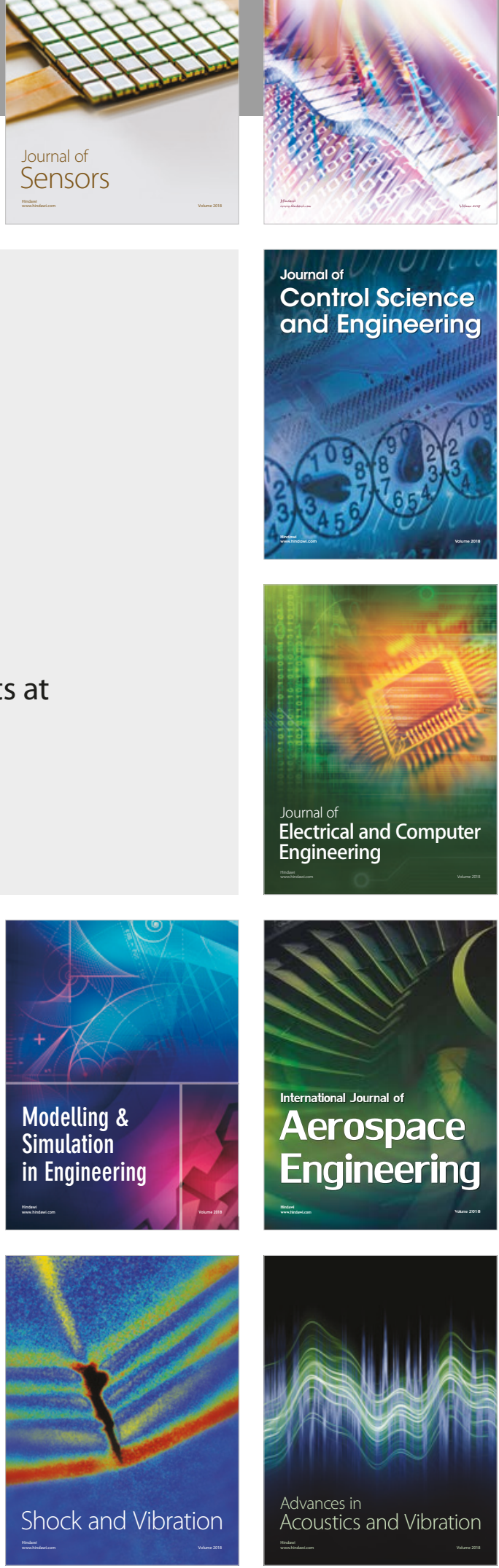